Revista Iberoamericana, Vol. LXVIII, Núm. 201, Octubre-Diciembre 2002, 997-1004

\title{
SAN MARTÍN EN LA FICCIÓN CINEMATOGRÁFICA: EL GENERAL Y LA FIEBRE, DE COSCIA Y FERNÁNDEZ BARAIBAR
}

\author{
POR \\ Alicia ChibÁn \\ Consejo de Investigación \\ Universidad Nacional de Salta-Argentina
}

DE LA HISTORIA Y LA LITERATURA, AL TEXTO FÍLMICO

Mucho se ha advertido acerca de las posibilidades de la ficción en cuanto a reponer lo que la historiografía calla, o a revertir imágenes heroizantes, desmitificándolas. En el caso particular de los grandes héroes de la Independencia, los Libertadores, constatamos que, en general y sobre todo en los países en donde se los considera los "Padres de la Patria”, más que la desmitificación obra el afán de penetrar en la complejidad de personajes y situaciones desde los fueros de la ficción. ${ }^{1}$

En el caso de San Martín, hay que tener en cuenta, como punto de partida, la vigorosa heroización fijada por los imaginarios sociales e históricos, sobre todo en Argentina. Martín Kohan (74) ha trazado los pasos seguidos por este proceso que primero construyó la imagen del héroe militar (con Juan María Gutiérrez y Sarmiento), para después representarlo como "Padre de la Patria" (en la historiografía fundacional de Bartolomé Mitre) hasta llegar a entronizarlo como "el Santo de la espada” (en la obra homónima de Ricardo Rojas). Y los modos de su actual vigencia no permiten dudar de que San Martín sigue presidiendo el panteón nacional para el imaginario argentino.

En cuanto a las ficciones literarias, si recorremos las más logradas que a él se refieren, dentro de un ámbito que incluye y rebasa la Argentina — como las de Ricardo Palma,

\footnotetext{
${ }^{1}$ Dentro de la gran profusión de novelas y cuentos históricos aparecidos en los últimos años en Latinoamérica, es evidente la despareja calidad literaria de los mismos. Se hace imprescindible, entonces, reconocer la existencia de una no escasa producción que tiene que ver sobre todo con expectativas de mercado y que tan bien caracterizara Guillermo Saavedra como "libros montados en la ola de una supuesta sed de exégesis chismosas (que) convierten la literatura en un sistema de tautologías” (12). Afortunadamente, son numerosos también los casos contrarios, en los que la ficción despliega sus más variados y específicos recursos para ofrecer, desde el imaginario artístico, nuevas lecturas y sentidos posibles de la historia. En muchos de estos textos encontramos la reconstrucción de las imágenes de los actores y de las situaciones históricas en función del "paradigma de la complejidad” (sostenido en el principio de conjunción e implicación de lo disímil), como un medio de acercamiento a las contradicciones, las incoherencias y la infinita multiplicidad del "mundo de la vida".
} 
Manuel Mujica Láinez, Enrique Anderson Imbert, Carlos Fuentes y Martín Kohan, ${ }^{2}$ sorprende, en todos los casos, la no centración estricta en su imagen. ${ }^{3}$

Esta es una de las cuestiones que llevan nuestro interés hacia El General y la fiebre, texto que, contrariando la dirección antes señalada, se propone el protagonismo y la centración de la figura sanmartiniana. Hay que tener en cuenta, por cierto, que abandonamos el terreno de las puras “narraciones literarias” — cuentos, “tradiciones” y novelas — para entrar en otro ámbito genérico y artístico que plantea cuestiones peculiares. Nuestro trabajo se basará tanto en el guión cinematográfico de Jorge Coscia y Julio Fernández Baraibar, como en su realización fílmica, dirigida por el mismo Coscia.

Algunas precisiones teóricas se nos imponen, como un paso previo para nuestro análisis. En primer lugar, es importante fijar las especificidades del guión y del filme, considerados ambos como textos, en el sentido amplio de "enunciaciones con fines comunicativos” (Hernández Esteve 203). El guión o libro cinematográfico — diferenciado del guión estrictamente técnico — contiene la "historia” verbalizada y dividida en escenas, con muy escasas indicaciones para el rodaje. ${ }^{4}$

Lo que peculiariza al guión es su carácter dependiente y efímero — virtual, diríamospues su función, paradójicamente, consiste en “desaparecer” tras la puesta en imágenes del filme. ${ }^{5}$ Éste, por su parte, es un texto sumamente complejo, resultante de la convergencia de una multiplicidad de códigos. Y en cuanto a los soportes que encauzan sus elementos significativos, hay que distinguir entre los que llegan al espectador por la "banda-imagen" (las imágenes propiamente dichas — “fotográficas, móviles y múltiples”- más las expresiones escritas que aparecen en la pantalla) y las correspondientes a la "bandasonido" ("el sonido fónico grabado, el sonido musical grabado y los efectos y ruidos”) (Hernández Esteve 208-10).

Teniendo en cuenta estas premisas, nos interesa demostrar los modos específicos por los cuales Coscia y Baraibar re-presentan actores y situaciones de claras referencias historiográficas.

En primer lugar, constatamos que si bien El General y la fiebre arriba a la complejización de la figura heroica por medio de motivos que ya encontramos en la

\footnotetext{
${ }^{2}$ Nos referimos a varias de las Tradiciones peruanas, de Ricardo Palma; “Un granadero”, de Manuel Mujica Láinez; "Patricio O’Hara, el Libertador”, de Enrique Anderson Imbert; La campaña, de Carlos Fuentes, y “Muero contento”, “El Libertador” y El informe. San Martín y el otro cruce de los Andes, de Martín Kohan. Hemos estudiado estos textos en "San Martín: de la Independencia a la ficción".

${ }^{3}$ Entendemos que esta "descentración” que dichos textos realizan, de ningún modo implican un “destronamiento desmitificador”. Antes bien, ellos retienen —y complejizan, eso sí-la heroización fijada en las mentalidades colectivas.

${ }^{4}$ Nos referimos a los filmes actualizadores de sistemas narrativos, que son la mayoría. Ellos difieren de los ejemplos menos frecuentes de cine experimental no narrativo. Sobre la narratividad cinematográfica, puede consultarse, dentro de una abundante bibliografía, Cine y literatura de Pere Gimferre.

${ }^{5}$ De muchos modos se ha insistido en esta característica. Acercamos dos ejemplos: "El guión es algo que se va a destruir” (Di Tella). "El guión es una hipótesis sobre algo que va a ser resuelto durante el rodaje" (Filipelli).
} 
ficcionalización novelesca o cuentísica de base histórica, como la enfermedad, ${ }^{6}$ la vida cotidiana o la introspección, ellos son manejados novedosamente desde la especificidad del lenguaje fílmico. Y en general, los más variados recursos de la imagen cinematográfica son aprovechados productivamente para ofrecer una re-lectura de un momento fundacional de nuestra historia, cargándolo de potenciales irradiaciones de sentido que se ofrecen a la recepción activa del espectador.

La estructura básica del filme - ya señalada en el guión que, digamos de paso, aparece muy levemente modificado en el rodaje — se asienta sobre el juego de escenas alternantes. Por una parte, se nos ofrece la serie que va desarrollando la historia principal, que en tanto acontecer "efectivo" es extremadamente sucinta: abarca el tiempo de la estadía de San Martín en la localidad cordobesa de Saldán —adonde fuera a reponer su salud, según está documentado—-, desde su llegada hasta la partida, lapso únicamente sobrepasado por la breve escena final que muestra al General cabalgando hacia los Andes. En esta historia tiene un papel preponderante un personaje femenino - Milagros, una joven criolla - construcción ficticia que abre múltiples posibilidades al relato, según veremos.

La alternancia se cumple entre las secuencias de este acontecer y las de una situación —alejada unos veinte años en el tiempo- que intermitentemente se intercala, originando nuevos sentidos y efectos: Milagros — ya mujer madura — narra los hechos de aquella historia a un viajero cuya identidad se preserva como secreto hasta casi el final, con lo cual se suscita la expectativa.

El filme, entonces, consta de una doble narración: la cinematográfica englobante y la puramente verbal, incluida en ella, lo que permite el contrapunto de los tiempos, pero sobre todo la contraposición entre "la vida vivida”, en la cual Milagros es agente, y "la vida narrada” (Ricoeur), de la que ella misma es emisora y organizadora. Y lo es desde una posición que en la narrativa clásica correspondería a la omnisciencia: expone sentimientos, sueños y obsesiones del protagonista, lo cual no deja de cuestionarse y de justificarse lógicamente (“-Y vos, mujer, ¿ ¿cómo conoces los sueños de ese hombre? ... En los sueños y en la muerte los hombres estamos solos”- dice el Viajero). Pero Milagros fue testigo de los delirios del General y esos delirios funcionan en el texto como el cauce de las profundidades psicológicas del personaje. La mujer actúa, así, en las escenas intercaladas, desde el lugar "del saber”, como informante, en contraste con la posición que ocupa en la historia principal: la de la ingenuidad y la ignorancia, fuertemente marcadas en sus interrogaciones: “¿Cómo es una batalla? (15), “¿Qué es una muchedumbre?” (76), “¿Qué es un traidor?” (87).

\footnotetext{
${ }^{6}$ Este motivo, por ejemplo, funda todo un sub-ciclo dentro de las ficciones referidas a Bolívar. Éste se inicia con "El último rostro", de Álvaro Mutis y se continúa en El General en su laberinto, de García Márquez — publicada en 1989, un año antes de la fecha del guión que analizamos—, en parte de El insondable, de Álvaro Pineda Botero y en La ceniza del Libertador, de Fernando Cruz Kronfly (ver Chibán y Altuna, comps.). En todos estos casos, la enfermedad aparece asociada a las postrimerías del héroe, lo que las diferencia netamente, en cuanto a su sentido y funcionalidad, del texto de Coscia y Fernández Baraibar.

${ }^{7}$ Consideramos como tal a las situaciones "vividas" por el personaje, diferenciándolas de las puramente imaginarias, a las que nos referiremos más adelante.
} 
LA ENFERMEDAD: MAL REAL, RECURSO NARRATIVO

Las biografías de San Martín dan cuenta de sus problemas de salud, entre ellos el grave malestar pulmonar que sufriera siendo joven. ${ }^{8}$ La enfermedad no es, por tanto, un motivo ficticio en el sentido de puramente imaginario, pero sí se convierte dentro del texto literario y fílmico, en un poderoso dispositivo del relato, que incide en el acontecer y en las construcciones del sentido. En primer lugar, y según ya lo adelantáramos, la enfermedad es tomada como un recurso aparentemente desmitificador, tal como fuera empleado en otras ficciones como las de García Márquez o Mutis, a las que ya nos referimos. Al igual que en estos textos, el "rebajamiento" sólo alcanza al héroe “de mármol y bronce”, pero otorgando otro tipo de engrandecimiento, de alta humanización, al héroe "real”. Si la dimensión del heroísmo se determina por la estatura del adversario, queda muy claro en el texto fílmico de Coscia que el protagonista se magnifica al desafiar a la enfermedad, constituida en un actante-oponente imperioso y fatal. De allí que hable de "la guerra" de sus propias entrañas (79) y que la sangre que vierte por su mal, alcance un estatuto metafórico que la asimila a la de las batallas pero también —y ello es importante como indicio anticipatorio del triunfo- al parto (15).

La enfermedad se corporiza en varios síntomas visibles en la imagen fílmica: temblor, disnea y una tos recurrente hasta el punto de escucharse, a veces, fuera del cuadro, “en off”. Pero el que adquiere una relevancia especial — ya advertida desde el título — es la fiebre, aprovechada como motivo de múltiples funciones y constituida en centro de una red metafórica. A ella se asocia, por ejemplo, el delirio, en su valencia patológica que revierte un estado de conciencia “normal”, pero también en el sentido de anhelo, de sueño utópico obsesivamente perseguido (el de la obtención de la libertad continental, que requiere el del cruce cordillerano, según veremos). Al extremarse esta obsesión, no deja de asimilarse a los signos de una "locura heroica”, explicitada en el decir del Viajero:

[...] es que hay dos clases de locos. Los que se quedan adentro para siempre ... y los que salen de ella con algo en la mano ... (Ríe) y vei mira lo que este loco sacó de su delirio [...] (89)

El estado febril, entonces, abre las puertas a las visiones oníricas y a las “apariciones”, esfumando los límites entre interioridad/exterioridad del personaje, ${ }^{9}$ sueño/vigilia, vida/

\footnotetext{
${ }^{8}$ Hay bibliografía específicamente dedicada a este tema, como La salud de San Martín y la medicina de su época, de Federido Christmann (La Plata: Asociación Cultural Sanmartiniana de La Plata, 1972), Cuáles fueron las enfermedades de San Martín, de Adolfo Galatoire (Buenos Aires: Plus Ultra, 1973) y Las enfermedades del general Don José de San Martín, de Mario Dreyer (Buenos Aires: Academia Nacional de Ciencias, 1980.

${ }^{9}$ Hay que tener en cuenta las dificultades que se plantean en el lenguaje cinematográfico para dar a conocer el mundo interior del personaje, dificultades muy fácilmente eludibles por el manejo del punto de vista y las posiciones de la enunciación en la ficción literaria. En El General y la fiebre el delirio es un canal apropiado para el conocimiento de la psiquis, hasta el de los planos más inconscientes, del protagonista. No falta tampoco aquel otro recurso, más tradicional, de la "voz en off” que intertextualiza el discurso epistolar del propio San Martín.
} 
muerte, o realidad/irrealidad. Es notable, en este sentido, que los cambios de escena acompañen estos vaivenes por los juegos temporales de amanecer/anochecer o los de la gestualidad: abrir/cerrar los ojos, acostarse/incorporarse, etc.

Una importancia especial adquieren las “visiones del delirio” como hábil estrategia amplificadora de ese tiempo que reconocimos como muy sucinto en la historia principal. Tengamos en cuenta que la inevitable selección que opera en todo relato — en la imposibilidad de la abarcación total de una "vida vivida”- es portadora, según el criterio que la guía, de la carga ideológica o interpretativa que ese relato conlleva. Pues bien, nuestro guión recorta — dijimos - ese interregno de las acciones militares en el cual San Martín debe restablecer sus fuerzas físicas. Sin embargo, las visiones oníricas que aparecen actualizadas, aportan otras instancias de su vida, proyectando la historia central hacia distintos tiempos. Así, las escenas bélicas localizadas en España y África, y las imágenes recurrentes del padre, reponen un pasado que instaura la problemática planteada incluso como cuestión de conciencia - del haber servido a la causa española, traicionándola posteriormente por la decisión patriótica de luchar desde y por América. Esta situación que hace converger en el personaje las categorías contrarias de "héroe” y de "traidor”, profundizan en gran medida la complejización de su figura. ${ }^{10}$

Por otra parte, las proyecciones hacia un futuro utópico y mediato que delinea las obsesiones y la misión que se impone el héroe, quedan plasmadas en el encuentro imaginario con Bolívar, pleno de simbolismos como el del "arroyo”:

\section{JINETE}

Ése es el arroyo que usted y yo cruzamos General ... y no hay retorno ... (confidente) Dígame ... sea sincero ... ¿¿Cuántas veces se ha arrepentido...? (62)

o aquel otro, marcado en el guión pero no filmado, de las circunstancias del abrazo de los dos Generales, empeñados en una tarea tan encumbrada en sus objetivos como penosa en su cumplimiento:

JINETE

Solo y enfermo, General ... sin ejército ...

\section{GENERAL}

Y a lomo de mula, General. Usted y yo a lomo de mula, como la revolución.

Los dos jinetes se abrazan, de mula a mula.

De todos modos, sí se inserta en el filme la expresión reiterada por San Martín a Bolívar: “-Hagámonos simultáneos”. En este punto, nos interesa señalar que ambos

\footnotetext{
${ }^{10}$ En este sentido, cuando Greimas y Courtés ( 206) caracterizan al héroe, lo conciben “dotado (...) de connotaciones eufóricas moralizantes, oponiéndolo al traidor (connotado disfóricamente).
} 
Libertadores aparecen equiparados en cuanto a sus dimensiones heroicas, lo cual no es frecuente en las plasmaciones que de cada uno de ellos encontramos en los imaginarios sociales, histórico-políticos y artísticos- de las diversas regiones latinoamericanas: en general, en los países que conformaron la Gran Colombia, el enaltecimiento —que llega hasta la instauración de un "culto" - de Bolívar, muchas veces conlleva una ignorancia o rebajamiento de la figura sanmartiniana; y lo contrario sucede, por ejemplo, en Argentina, donde San Martín está consagrado como el Libertador por antonomasia. ${ }^{11}$

TRAYECTORIA HEROICA Y APERTURAS DEL SENTIDO

Vemos así cómo la transformación visionaria de la realidad desde los enfoques subjetivos, permite ampliar los tiempos de la historia sanmartiniana. Y lo hace de tal modo que el relato fílmico presenta un itinerario típicamente "heroizante": el pasado se recuerda como el de la "decisión heroica” — y por eso mismo conflictiva — de abrazar la causa americana; el presente, instancia narrativa central, muestra detenidamente la "gran prueba” de la lucha contra la enfermedad y la desazón (como se explicita en el texto sobreimpreso al final). La victoria obtenida en este trance se alude redundantemente por los signos que marcan el paso de la disforia a lo eufórico: a la imagen de un General "sin huellas de la fiebre” (104), corresponde un escenario primaveral y, concomitantemente, se insertan, en la banda de sonido, “coplas”, una “vidalita”, un “triunfo” y la voz en off que da cuenta del nombramiento de San Martín como Gobernador de Cuyo, acto que cierra exitosamente la demanda de ese cargo al Director Posadas, incluida anteriormente en el texto (84).

Y por último, el futuro se prevé como el tiempo de la verdadera “tarea heroica” ${ }^{12}$ Ésta implica un objetivo mediato — la obtención de la libertad americana — connotado, según vimos, en la "visión” de Bolívar. Pero esa tarea conjunta supone y requiere otro programa de acción inmediata, que será el acto más notable de la trayectoria sanmartiniana: el cruce de los Andes para alcanzar, por una vía insospechada y estimada imposible, el Alto Perú. Esta instancia, si bien fuertemente valorizada por parte del relato y del saber del espectador, elide su desarrollo y, eficazmente, sólo se anticipa por medio del "montaje simbólico", ${ }^{13}$ que intercala la imagen del ascenso del protagonista a un promontorio, la del caballo en las alturas y la más reiterada de la Cordillera, ${ }^{14}$ antes de la partida final del General que "cabalga a su destino” (111).

\footnotetext{
${ }^{11}$ Una prueba de ello sería la controversia historiográfica planteada alrededor del enigmático “encuentro de Guayaquil” entre las tesis venezolana y argentina (ver Pérez Amuchástegui).

${ }^{12}$ La misión del héroe prototípico consiste en realizar acciones tendientes a "la recuperación de un orden”. Estas tareas deben, necesariamente, presentarse como importantes (para el "bien común”) y difíciles (por lo cual reclaman un "sujeto del hacer" que posea la máxima competencia). Para una caracterización del héroe desde un punto de vista semiótico, resultan de sumo interés los trabajos de Danuta T. Mozejko y Ricardo L. Costa, mencionados en la bibliografía.

${ }^{13}$ Tomamos este concepto de Mesa Falcón (37), quien lo considera en función de las relaciones entre las escenas-bases y las escenas intercaladas.

${ }^{14}$ En el guión figuran símbolos no incorporados en el filme, como el del vuelo de un pájaro, transformado luego en un cóndor cordillerano.
} 
Pero no se agota aquí — en la exposición de un itinerario heroico— el contenido ni la significación del filme. Sus estrategias de composición reservan hasta el final la gran "vuelta de tuerca" que disparará las líneas de sentido hacia un tramo mucho más amplio de la historia nacional. Esto tiene que ver con el enigma entrañado en la figura del viajero que, en las escenas alternantes, escucha el relato de Milagros: oculta siempre su rostro, no se lo nombra y el espectador sólo puede inferir un paralelismo con San Martín en virtud de dos rasgos implícitos tanto en la indumentaria como en las actitudes y en la gestualidad: el ser militar y el estar enfermo. Sin embargo se desliza, anticipadamente, un sutil indicio identificatorio para el conocedor de la historia argentina: el viajero abandona su pasividad y se enfurece, insultante, ante la sola mención de José María Paz. Éste fue, recordemos, dos veces vencedor de Facundo Quiroga, que no es otro que el misterioso personaje. ${ }^{15} \mathrm{Su}$ identidad se descubre con mayor seguridad, ya casi al terminar el filme, por una segunda información indicial — la que lo muestra "llegando a Barranca Yaco" (el sitio de su muerte) — hasta que en la escena subsiguiente se ve el rostro característico del riojano “con sus gruesas patillas y su expresión dura aunque fatigada por años y luchas” (110).

El montaje cinematográfico simultaneíza escenas distanciadas en el tiempo histórico (1814 y 1834). Al igual que en el caso de las dos llegadas que abren el texto fílmico, la conclusión pone en paralelo las dos partidas: la de San Martín, a caballo, y la de Quiroga, en galera, ambos escoltados. Pero allí se detienen las semejanzas en un brusco contraste: si el primero marcha hacia la gloria, el otro lo hace hacia la muerte. Desde las libertades de la ficción, el filme — después de representar a Quiroga recibiendo la información sobre la vida sanmartiniana — concluye con esta frase sobreimpresa: "El otro General se llevó esta historia a la tumba” (111).

Sin lugar a dudas, uno de los logros más notables del filme es su densidad sugerente, lograda por las varias estrategias constructivas que señalamos y muy especialmente por el hecho de que concluya encadenando aquellas escenas de las dos partidas de los militares. Al no otorgar continuidad a estas instancias — salvo en las fugaces escenas de marcha al pie de la Cordillera—, las detenciones de la cámara ante la inminencia de hechos claves en las vidas de ambos personajes, “postulan una realidad más compleja” que la representada -según el decir de Borges cuando señalaba los efectos de los varios modos de laconismo empleados por el arte "clásico". ${ }^{16}$

En El General y la fiebre, queda a cargo del espectador la interpretación de este juego de relaciones propuestas — de coincidencias y disparidades — entre dos periodos de la

\footnotetext{
${ }^{15}$ Podría considerarse también un indicio identificatorio —más sostenido— del personaje, la entonación provinciana — riojana- de su hablar.

${ }^{16}$ Además de la solución de continuidad como vía para aludir a esa “realidad más compleja”, Borges también indica otro procedimiento que, según vimos, emplea eficazmente El General y la fiebre para representar a San Martín y, más aún, a Quiroga: "la reducción de la vida entera de un hombre a dos o tres escenas”. Recordemos que cuando Borges trata esta cuestión —en "La postulación de la realidad” (Discusión, 221) y en el Prólogo a la primera edición de Historia universal de la infamia (289)_ - se refiere sobre todo al campo literario y de allí extrae la mayoría de los ejemplos. Sin embargo - y es lo que nos interesa — también reconoce la deuda que estos procedimientos selectivos tienen con el cine, y menciona a "las novelas cinematográficas de Josef von Sternberg, hechas también de significativos momentos” ( 221).
} 
historia nacional: el de los logros de la gesta independentista, y aquel tiempo subsiguiente de los intentos de “organización nacional”, encarnado en Quiroga —y quizás simbólicamente también abarcador de nuestros días-, tiempo de crisis y de dificultades antes que de continuación feliz de la herencia libertaria recibida.

\section{BiBLIOGRAFÍA}

Borges, Jorge Luis. "La postulación de la realidad”. Obras completas. Buenos Aires: Emecé, 1974.

Prólogo de la primera edición de Historia universal de la infamia. Obras completas. Buenos Aires: Emecé, 1974.

Coscia, Jorge y Julio Fernández Baraibar. El General y la fiebre. Guión cinematográfico. Buenos Aires, 1990.

Chibán, Alicia. “San Martín: de la Independencia a la ficción literaria”. Conferencia dictada en la Secretaría de Cultura de la Provincia de Salta-Argentina, el 11 de agosto de 2000.

y Elena Altuna (comps.).En torno a Bolívar: imágenes, imágenes. Salta-Argentina: Universidad Nacional de Salta, 1999.

Di Tella, Andrés y otros. El guión cinematográfico. Santa Fe: Instituto Nacional de Cinematografía-Universidad Nacional del Litoral. Consultado en Cine y narrativa. Universidad Nacional de Córdoba, 1994.

Gimferre, Pere. Cine y literatura. Barcelona: Planeta, 1985.

Greimas, A.J. y J. Courtés Semiótica. Diccionario razonado de la teoría del lenguaje. Madrid: Gredos, 1982.

Hernández Esteve, Vicente. Literatura y comunicación. Madrid: Instituto de EspañaEspasa Calpe, 1992.

Kohan, Martín. “De héroe militar a Santo de la Espada. La consagración histórica de José de San Martín”. Todo es historia XXXIV/397 (Buenos Aires, agosto, 2000): 74-85.

Mesa Falcón, Yoel. "La imagen encantada. Para una teoría del lenguaje cinematográfico”. Semiosis 21 (Xalapa-México, julio-diciembre 1988): 27-42.

Mozejko, Danuta Teresa. “La construcción de los héroes nacionales: una lectura semiótica de Juan Santamaría”. Fronteras: espacios de encuentros y transgresiones. García Ethel, comp. San José de Costa Rica: Universidad de Costa Rica, 1998. 121-48. y Ricardo Lionel Costa. "La circulación de los discursos”. Sincronía. Revista electrónica de estudios culturales. Guadalajara-México, Departamento de Letras de la Universidad de Guadalajara, invierno 2000.

"Poder hacer(se) la historia”. Versión española de “Constructing/Becoming History”. Current Sociology 48/2 (London, Thousand Oaks, CA y New Delhi, Sage Publications, April 2000): 33-58.

Pérez Amuchástegui, A. J. La "Carta de Lafond” y la preceptiva histográfica. Buenos Aires: Siglo XX, 1962.

Ricoeur, Paul. "La vida: un relato en busca de narrador”. Educación y política. Buenos Aires: Docencia, 1984. 45-58.

Saavedra, Guillermo. Prólogo a Cuentos de historia argentina. Buenos Aires: Alfaguara, 1998. 11-16. 